
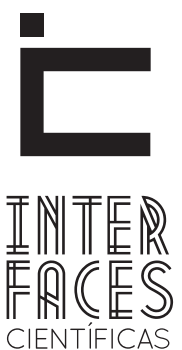

DIREITO

\title{
A AVALIAÇÃO DE IMPACTO AMBIENTAL E A RESPONSABILIDADE DO BRASIL DIANTE DA DEGRADAÇÃO AO MEIO AMBIENTE
}

Isabelle Dias Carneiro Santos ${ }^{1}$

\section{RESUMO}

A Avaliação de Impacto Ambiental surgiu como resposta jurídica para o desenvolvimento econômico dos Estados alinhado a uma proteção ambiental de seus recursos naturais, sendo hoje tida como um dos principais instrumentos do Direito Ambiental, tanto na esfera interna quanto internacional. Ocorre que com a alteração da classificação do desenvolvimento econômico brasileiro de país subdesenvolvido para Estado em desenvolvimento, a avaliação de impacto ambiental passou a ser cada vez mais necessária, porém nem sempre observada em seus resultados quanto à concessão da licença ambiental, o que pode ocasionar prejuízos para as gerações futuras.

\section{PALAVRAS-CHAVE}

Avaliação de Impacto Ambiental. Dano Ambiental. Desenvolvimento Sustentável.

\section{ABSTRACT}

The Evaluation of Environmental Impact arose emerged as a legal response to the economic development of States aligned with an environmental protection of his natural resources, today is regarded as one of the main instruments of environmental law, both at the national and international sphere. That occurs with the change of the classification of the Brazilian economic development of underdeveloped country for developing State; the evaluation of environmental impact became increasingly necessary, but not always seen in its results for the granting of the environmental license, which can cause harm to future generations.

\section{KEYWORDS}

Evaluation of Environmental Impact. Environmental Damage. Sustainable Development. 


\section{RESUMEN}

La Evaluación de Impacto Ambiental surgió como respuesta jurídica para el desarrollo económico de los Estados asociado a una protección ambiental de sus recursos naturales, siendo hoy vista como uno de los principales instrumentos del derecho ambiental, tanto en la esfera interna cuanto internacional. Ocurre que con la alteración de la clasificación del desarrollo económico brasileño de país subdesarrollado para Estado en desarrollo, la evaluación de impacto ambien- tal pasó a ser cada vez más necesaria, pero ni siempre observada en sus resultados cuanto a la concesión de la licencia ambiental, lo que puede ocasionar perjuicios para las generaciones futuras.

\section{PALABRAS CLAVE}

Evaluación de Impacto Ambiental. Daño Ambiental. Desarrollo Sustentable.

\section{INTRODUÇÃO}

O Brasil, juntamente com outros países em desenvolvimento, como a Índia e a China, é um dos Estados que mais investimentos vêm abrigando tanto de âmbito nacional quanto internacional, levando o governo a implantar grandes empreendimentos industriais que vão desde a mineração, álcool, petróleo, dentre outros campos de atividade que vêm gerando empregos e crescimento econômico para o país.

Diante de tal realidade e com o escopo de evitar ou, ao menos, minimizar o agravamento da poluição e outras formas de impactos ambientais negativos, medidas de proteção ao meio ambiente vinculadas ao desenvolvimento vêm sendo utilizadas, incluindo nesse rol a Avaliação de Impacto Ambiental (AIA).

Esse mecanismo, que faz parte da Política Nacional de Meio Ambiente (PNMA), é hoje um dos instrumentos preventivos mais disseminados no mundo, inclusive no que tange à possibilidade de criar soluções diante de casos marcadamente degradantes ao meio ambiente, mas de significativo interesse para o desenvolvimento sustentável, motivo pelo qual passou a exercer grande importância no campo da proteção ambiental.

Ocorre que, mesmo prevista como proteção tanto na legislação nacional como em documentos internacionais, no mundo prático há situações em que o Estado decide pelo desenvolvimento e coloca em xeque a proteção ao meio ambiente, fazendo com que o equilíbrio ecológico disposto expressamente na atual Constituição Federal Brasileira ceda espaço para interesses de âmbito político-econômico.

A priori, tal atitude pode não trazer prejuízos imediatos, todavia, ao longo dos anos os malefícios decorrentes de decisões da Administração Pública podem gerar danos irreversíveis ao meio ambiente, inserindo no rol de prejudicados a fauna, a flora e a própria espécie humana. 


\section{BREVE HISTÓRICO DA AVALIAÇÃO DE IMPACTO AMBIENTAL}

\subsection{NA ESFERA INTERNACIONAL}

A Avaliação de Impacto Ambiental (AIA) surgiu pela primeira vez no mundo a partir de estudos desenvolvidos nos Estados Unidos da América (EUA), com a promulgação do National Environmental Policy Act - NEPA (Lei da Política Nacional do Meio Ambiente), seguindo-se a esta, outras pesquisas e medidas na Europa em função da evolução dos problemas relacionados ao desenvolvimento econômico desvinculado da proteção ao meio ambiente (MILARÉ, 2011).

Diante de tal realidade, a Avaliação de Impacto Ambiental passou a ser exigida a partir da década de 1960 quando se consolidou o conceito de Impacto Ambiental, conceito esse necessário para se estabelecer o que pode ser objeto da AIA, bem como o que é considerado ou não dano ao meio ambiente.

Apesar de já existir esse instrumento de proteção no âmbito interno de alguns países, somente duas décadas depois é que a AIA é institucionalizada em nível mundial em função dos resultados obtidos após a Conferência das Nações Unidas Sobre Meio Ambiente de 1972, na Suécia, ocasião em que foi votado um conjunto de recomendações, dentre as quais um plano relativo à avaliação do meio ambiente mundial, chamado de "Plano Vigia" (SOARES, 2003), sendo essa a primeira conferência sobre o meio ambiente de nível global.

Duas décadas mais tarde, com o advento da Conferência da Organização das Nações Unidas sobre Meio

\subsection{NO ÂMBITO DO TERRITÓRIO BRASILEIRO}

No Brasil, a Avaliação de Impacto Ambiental (AIA) aparece na década de oitenta com a Lei $6.803 / 80$, que trata do zoneamento industrial em áreas críticas de poluição em razão de exigências de organismos mul-
Ambiente e Desenvolvimento de 1992 no Rio de Janeiro, mais conhecida como ECO/92 ou Rio/92, a Avaliação de Impacto Ambiental se tornou um princípio ambiental consubstanciado em tratados internacionais (Princípio 17 da Declaração do Rio/92), estabelecendo que a AIA é um instrumento nacional para efetuar atividades planejadas de cunho social, econômico e ambiental que possam vir a ter um impacto adverso sobre o meio ambiente.

A partir desse documento internacional a Avaliação de Impacto Ambiental passa a ser prevista como: "[...] instrumento nacional, que deve ser empreendida para as atividades planejadas que possam vir a ter impacto negativo considerável sobre o meio ambiente, e que dependam de uma decisão de autoridade nacional competente" (ONU, 1992).

Com o advento presente século outra grande Conferência das Nações Unidas foi realizada no ano de 2012, com a participação de mais de cento e oitenta países, Conferência essa intitulada de Rio + 20. Apesar de se esperar grandes resultados quanto a investimentos para a proteção ao meio ambiente, em virtude da crise econômica mundial muito do que se desejava, a priori, não teve o desfecho esperado, revelando-se frustrante. Mesmo assim, o mundo continua preocupando-se e concentrando-se em questões de sustentabilidade e preservação ambiental.

tilaterais que financiavam projetos do governo brasileiro passando a fazer parte definitivamente do ordenamento jurídico nacional em $1981 \mathrm{com}$ a criação da Política Nacional de Meio Ambiente (PNMA) por meio 
da Lei 6.938/81, em que se tem como exemplo de submissão de projetos financiados por organismos multilaterais a Hidrelétrica de Sobradinho no estado da Bahia, que foi bancada pelo BID - Banco Internacional de Desenvolvimento (GRANZIERA, 2011).

Posteriormente tal instrumento de proteção ambiental foi aperfeiçoado com a Resolução 01/1986 do Conselho Nacional de Meio Ambiente (Conama) que prevê critérios e diretrizes para o uso e implementação da AIA, bem como a elaboração de Estudos Prévios de Impacto Ambiental (Epia) e de seu respectivo Relatório de Impacto ao Meio Ambiente (Rima) para atividades efetivamente causadoras de significativa degradação ambiental (BELTRÃO, 2008).

Essa Resolução do Conama também trouxe em seu art. $1^{0}$ e incisos a definição de Impacto Ambiental, como forma de aclarar quando a AIA se faz necessária, sendo entendido como:

[...] qualquer alteração das propriedades físicas, químicas e biológicas do meio ambiente causada por qualquer forma de matéria ou energia resultante das atividades humanas que direta ou indiretamente, afetam: a saúde, a segurança e o bem- estar da população, as atividades sociais e econômicas, a biota, as condições estéticas e sanitárias do meio ambiente, a qualidade dos recursos ambientais. (CONAMA, 1986)

Ainda na década de 1980 a Avaliação de Impacto Ambiental (AIA) foi abordada em nível constitucional com a promulgação da Constituição da República Federativa do Brasil de 1988, valendo frisar que essa constituição foi a primeira no mundo a inscrever a obrigatoriedade da AIA em nível constitucional, dis-

\section{A AVALIAÇÃO DE IMPACTO AMBIENTAL COMO MECANISMO DE PROTEÇ̃̃O NACIONAL}

A Avaliação de Impacto Ambiental como instrumento da Política Nacional de Meio Ambiente tem por correndo sobre o tema em seu artigo $225, \S 1^{\circ}$, IV, que prevê:

$\S 1 .^{\circ}$ Para assegurar a efetividade desse direito, incumbe ao poder público:

IV. exigir, na forma da lei, para instalação de obra ou atividade potencialmente causadora de significativa degradação do meio ambiente, estudo prévio de impacto.

Seguindo os moldes da Constituição Federal, boa parte dos Estados da federação também começou a inserir o assunto em suas constituições estaduais, como nos casos da Bahia, Mato Grosso do Sul, São Paulo, Sergipe, bem como o Distrito Federal por meio de sua Lei Orgânica.

Com o início dos anos noventa a AIA passou a ter relação estreita com o licenciamento ambiental após a elaboração do Decreto 99.274 de 1990, sendo um dos critérios para a concessão da licença ambiental para implantação de determinado empreendimento ou realização de atividades ou obras.

Já em 1997 há a criação da Resolução nº 237 do Conama que derroga a Resolução n01/86 e complementa o procedimento de licenciamento ambiental, tratando também no seu bojo da avaliação de impacto ambiental (BELTRÃO, 2008).

Percebe-se claramente que a Avaliação de Impacto Ambiental passou a ter significativa importância nacional e internacional a partir de meados do Século XX em virtude de um progressivo desenvolvimento econômico-social e da necessidade de vinculá-lo a uma proteção ambiental dos recursos necessários a esse desenvolvimento.

escopo avaliar previamente os impactos ambientais diante da instalação de atividades consideradas poten- 
cialmente poluidoras, antevendo riscos decorrentes do empreendimento sendo a AIA uma das etapas procedimentais para a concessão da licença ambiental.

Vale frisar que não se deve confundir a AIA com a Avaliação Ambiental Estratégica (AAE). Aquela é tratada no plano prático por meio de um conjunto de procedimentos de planejamento e controle do meio ambiente, enquanto essa se limita ao plano das ideias por meio de projetos e políticas programáticas, para o desenvolvimento sustentável vinculado a um equilíbrio ecológico (MILARÉ, p. 465).

Ainda no que concerne a AlA, ela é o gênero que abarca duas principais espécies no que tange a análise prévia dos impactos de quaisquer atividades humanas passíveis de causar danos significativos ao meio ambiente, ou seja, o Estudo Prévio de Impacto Ambiental (Epia) e o Relatório sobre Impacto ao Meio Ambiente (Rima).

Diferentemente da AIA, o Epia e o Rima somente são determinados obrigatoriamente pelo órgão pu-

\section{A AVALIAÇÃO DE IMPACTO AMBIENTAL VERSUS AS POLÍTICAS GOVERNAMENTAIS}

Apesar do que prega a legislação nacional no que tange à preservação ambiental vinculada ao desenvolvimento socioeconômico, na prática não é sempre o que vige, podendo o poder público por vezes, em função de interesses político-econômicos, se sobrepor aos interesses ambientais.

Nesse mesmo sentido Édis Milaré afirma que: “... apesar dos inegáveis benefícios trazidos para a preservação do meio ambiente, não podemos negar que ainda há, infelizmente, uma enorme distância entre aquilo que prevê a lei e o que ocorre, de fato, na realidade deste imenso Brasil” (MILARÉ, 2011). blico diante de atividades e obras que possam causar potencial e significativa degradação ambiental (SIRVINSKAS, 2012).

Em linhas gerais o EPIA é um instrumento administrativo preventivo de nível constitucional (art. 225, $\S 1^{\circ}$, IV da CF). É uma avaliação mediante estudos que analisam a viabilidade ou não da instalação da indústria ou exercício da atividade causadora de significativa degradação ambiental com a apresentação, inclusive, de alternativas tecnológicas por meio de estudos efetuados por uma equipe técnica multidisciplinar, em que se busca assegurar o menor grau de impacto possível.

Já o Rima, constitui um resumo do Epia no qual se aborda os pontos fundamentais do estudo elaborado numa linguagem mais acessível, sendo instrumento de comunicação do Epia tanto ao administrador quanto ao público com a finalidade de aclarar as possíveis consequências ambientais do projeto e suas alternativas, comparando as vantagens e desvantagens.

Essa realidade é possível de se verificar de norte a sul do país, seja por meio da mídia ou mesmo in loco, casos em que uma vez verificado o agente poluidor e causador de degradação ambiental, haverá a responsabilização dele, podendo responder nas esferas administrativa, civil e penal.

Tal medida serve para tanto para as pessoas físicas, como para as pessoas jurídicas, sejam elas de direito privado ou público. Porém a questão a se contestar diz respeito à pessoa jurídica de direito público, uma vez que é a Administração Pública que decide pela concessão ou não da licença ambiental. 
Sucede que findado todo o procedimento de licenciamento, com a elaboração da AIA para todos os casos de licenciamento com estudos técnicos ambientais, o Epia e seu consequente Rima para obras ou empreendimentos considerados significativos causadores de potencial degradação ambiental, mesmo havendo uma posição da equipe técnica multidisciplinar desfavorável à concessão da licença ambiental, o poder público ainda pode decidir discricionariamente de modo diverso ao parecer da equipe.

Nessa situação deverá tão somente motivar sua decisão, mas isso não impede que do seu ato não possa decorrer danos futuros ao meio ambiente e à sociedade como um todo.

Justamente por ser o direito ambiental considerado um direito de proteção das gerações de hoje e do porvir sendo, portanto, transgeracional, é que os danos ambientais resultantes das medidas estatais, sejam eles diretos ou indiretos, uma vez concluindo o Epia e verificada a possibilidade de consequências adversas ao meio ambiente, o poder público deveria decidir acompanhando o entendimento de estudos técnicos e bem fundados da equipe técnica multidisciplinar.

Como não é isso que vigora, das decisões que levam aos impactos negativos o poder público passa a ter responsabilidade objetiva pela degradação podendo sempre figurar no pólo passivo de qualquer demanda que tenha por finalidade reparar o meio ambiente. Caso o dano tenha sido ocasionado por intermédio de um de seus agentes o Estado será ao menos responsável solidariamente, pois cabe aos órgãos ambientais não só impedir o dano, como também fiscalizar os atos de seus funcionários e órgãos ambientais.

Mesmo tendo o Estado a atribuição de coibir a degradação ao meio ambiente vê-se, no entanto, que há uma predileção pelo reparar ao invés do prever e prevenir o dano, não observando a Administração Pública, em razão de suas políticas governamentais, os princípios de direito ambiental da prevenção e da precaução fazendo-se necessário utilizar a máquina judiciária para sanar e/ou por fim ao dano decorrente de sua decisão (CANOTILHO, 2007).

Ocorre que mesmo que o poder público seja responsabilizado por meio de Ação do Ministério Público ou de entes sociais, a sua decisão contrária à avaliação proveniente de Estudo Prévio de Impacto Ambiental e de Relatório Ambiental ao Meio Ambiente pode ocasionar situações em que o impacto negativo decorrente da concessão de licença ambiental será permanente e irreparável.

Para que a decisão de concessão da licença ambiental em desacordo com os pareceres técnicos que entendam ser o empreendimento, atividade ou obra do proponente causador de danos não só à natureza, mas também à saúde da população, mister que o poder público esteja vinculado ao Epia diante dessa situação específica, agindo discricionariamente somente nos casos de parecer favorável conforme sua conveniência.

\section{CONSIDERACÕ̃ES FINAIS}

O Brasil nas últimas décadas vem experimentando uma evolução econômica que a muito não se vivenciava. Porém, à medida que a consciência ambiental cresce no país, discussões a respeito da preservação ao meio ambiente vinculadas ao desenvolvimento

sócio-econômico surgem no âmbito governamental, acadêmico e mesmo popular.

Esses debates se aprofundam justamente em função do Direito Ambiental ter como uma de suas 
características basilares ser transgeracional e de se verificar que na prática não é raro que empreendimentos são implantados à margem do que prevê a Política Nacional de Meio Ambiente e os Tratados Internacionais dos quais o Brasil é signatário em prol de interesses político-econômicos, o que pode inclusive colocar em xeque o desenvolvimento sustentável tão necessário para o progresso do país.

Vale ressaltar que qualquer pessoa física ou jurídica, de direito público ou privado, que venha a causar diretamente ou indiretamente impactos adversos ao meio ambiente será responsabilizada pelos danos ambientais que venha a causar.

No caso dos órgãos ambientais, pessoas jurídicas de direito público, sua postura diante da proteção ambiental deve ser mais exemplar e responsável ainda, pois sua decisão calcada em interesses outros que não seja a proteção ambiental vinculada ao desen-

\section{REFERÊNCIAS}

BRASIL. Constituição da República Federativa do Brasil de 1988.

BRASIL. Lei 6.803/80 de 02 de julho de 1980.

BRASIL. Decreto 99.274 de 1990.

BELTRÃO. Antônio F. G. Aspectos jurídicos do estudo de impacto ambiental. MP Editora. São Paulo. 2008.

CANOTILHO, J.J. Gomes. LEITE. José R. Morato (Org.) Direito constitucional ambiental brasileiro. São Paulo: Saraiva, 2007.

CONAMA. Conselho Nacional de Meio Ambiente. Resolução nº 01 de 1986. volvimento pode prejudicar o meio ambiente em seu sentido lato sensu e o próprio crescimento econômico e, por conseguinte a própria população nacional.

Desse modo a observância a Avaliação de Impacto Ambiental, instrumento de proteção prévia do meio ambiente e de importância imprescindível para a preservação ambiental e, as suas espécies Estudo Prévio de Impacto Ambiental (Epia) e Relatório de Impacto ao Meio Ambiente (Rima), faz-se cada vez mais necessária.

Por tal motivo, a Avaliação de Impacto Ambiental não deve ser tida como mero requisito formal do procedimento do licenciamento para a concessão da licença ambiental, devendo ser tratada como meio de planejamento ambiental, não devendo o poder público agir de modo discricionário, mas vinculado quando o Estudo Prévio de Impacto Ambiental concluir pela não concessão da licença ambiental.

CONAMA. Conselho Nacional de Meio Ambiente. Resolução nº 237 de 1997.

GRANZIERA. Maria Luiza Machado. São Paulo: Atlas, 2011.

MILARÉ, Édis. Direito do Ambiente. Gestão ambiental em foco. 7. ed. São Paulo: Revista dos Tribunais, 2011.

SIRVINSKAS, Luís Paulo. Manual de direito ambiental. São Paulo: Saraiva, 2012.

SOARES, Guido Fernando Silva. Direito internacional do meio ambiente. São Paulo: Atlas, 2003. 
ORGANIZAÇÃO DAS NAÇÕES UNIDAS. Declaração sobre meio ambiente e desenvolvimento. Adotada na Conferência do Rio de Janeiro sobre Meio Ambiente e Desenvolvimento de 1992. Disponível em: <www.cedin.com.br>. Acesso em: 21 ago. 2012. 